\title{
Intravenous Fluid Therapy in Adults and Children
}

\author{
L P C Warnapura ${ }^{1 *}$, T M Peiris ${ }^{2}$ \\ Locum consultant in anaesthesia and intensive care ${ }^{I^{*}}$, Consultant anaesthetist with special \\ interest in paediatric anaesthesia ${ }^{2}$ \\ Luton and Dunstable University Hospital, UK.
}

*Corresponding author: chamarawarnapura@gmail.com

\begin{abstract}
Evidence behind rational fluid therapy for sick paediatric and adult patients is sparse. During the last two decades, fluid therapy has become increasingly regulated. The neverending debate about crystalloids versus colloids is continuing and the scientific community still waits the discovery of the ideal intravenous solution. This review focus on analyzing the current evidence behind various practices of fluid management in children and adults.

A web based search was carried out using the pubmed. The following key words were used; "Fluid therapy", "peri-operative fluids", "tissue oxygenation", "Intravenous fluids", "tissue perfusion". Studies more than 10 years old were excluded. Systemic reviews, randomized trials, meta analyses and novel ideas about fluid resuscitation were filtered out to obtain the best evidence. "Up to date" 2016 was used to formulate factual back ground information.
\end{abstract}

Keywords: Fluid therapy; peri-operative fluids; tissue oxygenation; intravenous fluids; tissue perfusion

\section{Introduction}

The first salt solution to rehydrate patients was given intravenously during the Cholera epidemic by William O'Shaughnessy in $1831 .{ }^{1}$ Since then intravenous fluid therapy was subjected to much scrutiny. Today, fluid therapy is probably the most common therapeutic intervention in surgical as well as critically ill adults and children. ${ }^{2}$ Generally, intravenous fluid therapy is used to counteract blood loss or decreased preload. In anaesthetic practice intravenous fluid is commonly used when vasomotor tone is reduced by anaesthetic agents, which could lead to considerable hypotension. In sepsis induced vasoplegia, there is vasodilatation with sequestration of blood in the unstressed blood compartments added with poor vascular compliance. Almost all of the administrative fluid is sequestrated in tissues resulting in severe oedema which leads to vital organ dysfunction. ${ }^{3}$

Tissue perfusion can get compromised with hypovolemia, normovolemia, or hypervolemia. Impaired tissue perfusion is commonly seen when the cardiac output is reduced or when there is profound vasoconstriction in blood vessels even with a normal cardiac output. In converse, ineffective tissue perfusion occurs when tissue oxygen demand overweighs the supply. Hypervolaemic reduced tissue perfusion is seen in cardiac failure.

Fluid resuscitation is aimed to normalise organ perfusion. When optimal, the end-diastolic volume of the left ventricle generates an adequate stroke volume. This is seen where the circulating blood volume is restored at least to within 15 to 20 percent of normal. $^{4}$ Normalization of heart rate and blood pressure may indicate adequate perfusion in healthy patients but may be unreliable in critically-ill patients.

It is important to identify the two types of oxygen transport to cell mitochondrium namely convective oxygen transport and diffusion oxygen transport. Former is related to the oxygenated red cells while latter depends on the pressure gradient and inversely related to the distance between the capillary and the mitochondria within the cell. If this distance 
increases specially in sepsis, which is associated with fluid leakage, there will be considerable mitochondrial hypoxia.

On the other hand, in acute blood loss, oxygen transporting capacity could be affected and certainly helped by providing the pressure needed by administering intravenous fluids or blood. 2015 NICE guidance for blood transfusion recommends a threshold of 70 $\mathrm{g} /$ litre and a post transfusion haemoglobin concentration of 70-90 g/litre when considering a restrictive strategy for blood transfusion. It further recommends to consider one unit of red blood cell transfusion for adults or equivalent volumes calculated on body weight for children provided there is no ongoing bleeding. ${ }^{5}$

\section{Colloid Vs Crystalloids}

The long-standing debate of crystalloid vs colloid controversy has not yet provided robust evidence from randomized control studies to suggest either have done any better apart from increased mortality with hydroxyl ethyl starch. ${ }^{6}$ Place of albumin as a resuscitation fluid has long being debated since the SAFE study. ${ }^{7}$ However, no differences in 28 days mortality, multi organ failure, duration of hospital stay or effects on systemic $\mathrm{pH}$ was revealed by the study with or without sepsis. ${ }^{8,9}$ In patients with head trauma, resuscitation with albumin was associated with higher mortality than resuscitation with saline. ${ }^{10}$

\section{Monitoring microcirculation}

It is increasingly evident that microcirculation is the key for oxygenation than traditional invasive and non-invasive pressure measurements. An ideal substance for carrying (and delivering) oxygen would have similar properties to red blood cells, as well as a long shelf-life, cost effectiveness, and minimal side effects. Two major categories of oxygen carriers that have been developed and studied are haemoglobin-based carriers and perfluorocarbons. Admittedly, monitoring microcirculation is very challenging in clinical practice. There are various tools available and reviewed on monitoring microcirculation. ${ }^{11}$ Among them, third generation hand held and user friendly microscope (Cytocam-Incident Dark Field) is gaining much popularity because of good quality images shown. This is a pen

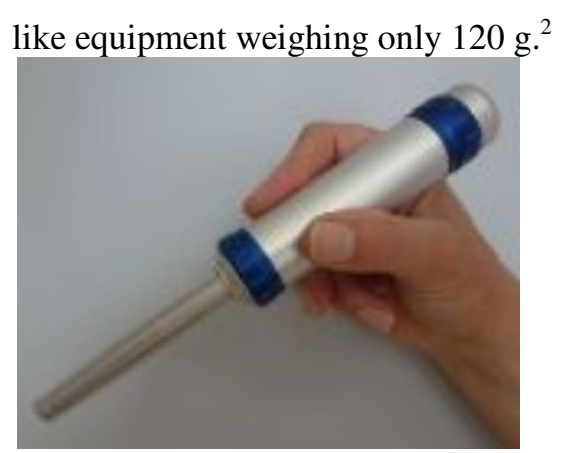

Figure 1. Cytocam-Incident Dark Field microscope.

By studying microvascular dysfunction one can get information not only about organ dysfunction but, also regarding the severity of sepsis. ${ }^{6}$ Other tools such as Laser Doppler has been proposed for investigating microcirculation. These can measure skin perfusion of critically ill patients.

\section{The Glycocalyx}

The Glycocalyx, which is the covering of endothelial cells, plays an important role in the development of microcirculatory alterations. It is shown that microcirculatory derangement can be present even when the haemodynamics are stable. ${ }^{3}$ Cardiac filling pressure with excessive fluid loading can trigger release of natriuretic peptide which is believed to be assisting fluid removal. Natriuretic peptide cleaves membrane bound protoglycans and glycoproteins off the endothelial glycocalyx. This results in rapid shift of intracellular fluid into the interstitial space which indeed increase the extravascular lung water. It is shown that, increased extravascular lung water is a proven marker of death. ${ }^{12}$

\section{Doubtful practices}

Fixed-volume fluid administration based on algorithms are not advocated anymore because, they tend to cause fluid overload. ${ }^{13}$ Contradictory evidence has been produced by clinical trials assessing the effects of fluids over the outcome of the surgery. Reviewing the evidence for current fluid therapy suggests that little is evidence-based. Certain practices namely, considering the non-existing 3rd space losses for fluid calculations; overestimating losses from evaporation via abdominal cavity;

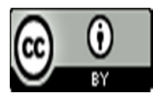

(C) 2017. Warnapura et al. This is an Open Access article distributed under the terms of the Creative Commons Attribution License (http: //creativecommons.org/licenses/by/4. 0), which permits unrestricted use, distribution, and reproduction in any medium, provided the original work is properly credited 
ineffective volume preload aimed to prevent hypotension in neuraxial blocks and differences in fluid distributions in traumatized tissues all contribute to such unproven practices. Evidence backing goal-directed fluid therapy and restricted intravenous fluid therapy are also not without their limitations. Current evidence however supports restricted intravenous fluid therapy which aims at replacing the losses while avoiding fluid overload.

\section{Evidence for restricted and goal directed fluid therapy}

According to a systematic review and metaanalysis restricted fluid therapy for patients having major abdominal surgeries significantly reduces the risk for pneumonia and pulmonary edema. ${ }^{14}$ It also improves bowel recovery, shortens mean time to first bowel movement and the hospital stay.

Several meta-analyses for goal-directed fluid therapy compared with other fluid regimens has shown improved clinical outcomes. ${ }^{15,16,17,18}$ These include lower risk of respiratory, renal, and gastrointestinal complications, and shorter time to return of bowel function and hospital discharge. A 2014 systematic review and metaanalysis focusing on goal directed fluid therapy confirmed this by having reduced incidence of complications, postoperative infection and a trend in reduction in hospital 28-day and 30day mortality. However, the duration of hospital stay increased slightly. This evidence was questioned by the fact of having nonuniform definitions for goal directed fluid therapy and including several older studies.

In contrary, a randomized trial of 734 high-risk patients $\geq 50$ years of age undergoing major gastrointestinal surgery at 17 acute care hospitals in the United Kingdom, the use of a cardiac output-guided haemodynamic therapy did not significantly reduce the composite outcome of complications and 30-day mortality compared with usual care. ${ }^{19}$ In a double-blind randomized multicenter trial including 150 patients undergoing elective colorectal surgery, goal-directed fluid therapy to optimize stroke volume offered no significant benefit with respect to postoperative outcome over fluid therapy using zero balance strategy and postoperative normal body weight. ${ }^{20}$

However, when comparing goal directed and restrictive fluid therapy with fixed volume regimens a significant improvement in length of stay, earlier return of bowel function, and decreased complications (eg: pneumonia) was noted. There were no consistent reductions over mortality rate. Data suggests, restrictive management of fluid therapy was likely to reduce and improve outcome in sepsis. ${ }^{3}$

\section{FEAST trial}

In paediatrics, fluid protocols are ever changing and has gone through interesting landmarks over the years. The most recent surprise is the FEAST trial (Fluid Expansion as Supportive Therapy) which almost gave a shock to policy makers regarding fluid boluses in critically ill children. This multicenter randomized control study was a trial conducted in Africa on children with febrile diseases mainly with malaria. ${ }^{21}$ One group was given one fluid over 1hour $20 \mathrm{ml} / \mathrm{kg}$ with $0.9 \%$ saline or albumin followed by maintenance $2-4 \mathrm{ml} / \mathrm{kg}$. The other group was randomized to give fluid boluses. The mortality after 48 hours showed $7.3 \%$ in the group who didn't receive boluses verses $10.5 \%$ mortality in the group which received boluses. There was no difference in the outcome between albumin and saline.

\section{Newer concept}

A novel conceptual framework for fluid management in critical illness introduces the idea of interrelated phases of fluid management differentiated according to the clinical status of the patient with evolving goals for fluid need. ${ }^{22}$ It recognizes the need to tailor fluids to specific indications with time and phase dependent variables. This concept identifies the need to move away from a "one size fits all" approach for the early phases of fluid therapy. Accordingly, four phases of fluid therapy are identified: Salvage, Optimisation, Stabilisation and De-escalation. Numerous studies in perioperative and critical care settings support this concept of "ebb and flow" in fluid loading, fluid accumulation and removal. Indeed, these phases of resuscitation likely exist on a continuum and the observed variability in fluid balance is understood to be a dynamic process, which does not necessarily follow a fixed

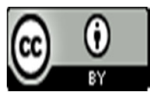

(C) 2017. Warnapura et al. This is an Open Access article distributed under the terms of the Creative Commons Attribution License (http: //creativecommons.org/licenses/by/4. 0), which permits unrestricted use, distribution, and reproduction in any medium, provided the original work is properly credited 
temporal pattern or time scale and is likely tobe highly individualized.

\section{Dengue Shock Syndrome (DSS)}

Over the last few decades painful lessons were learnt from the fluid management in DSS in Sri Lanka. Judicious intravenous fluid resuscitation is essentially the main treatment for DSS. ${ }^{23}$ During fluid resuscitation, larger volumes of fluids are administered for predetermined periods of time under close monitoring to evaluate the responsiveness and to avoid the development of pulmonary oedema. It is evident that such monitored fluid therapy has changed the outcome of DSS.

As mentioned at the beginning of this article, intravenous fluid therapy is the commonest intervention we carry out as medical professionals. If we do an error in this intervention, especially in critically ill patients, it could do a major harm. It is important to use the current evidence and do more research such as FEAST trial to find the best practice in fluid therapy to improve patient care.

\section{Salvage Phase}

- Initial phase of acute resuscitation.

- Aim to restore effective circulating blood volume, organ perfusion and tissue oxygenation.

- Relies on a combination of clinical and haemodynamic parameters, near-patient diagnostics.

- Fluid accumulation and a positive fluid balance expected.

- Reassessment and re-challenge performed without the clinician leaving the bedside.

- Requires constant observation of the patient's haemodynamics to prevent life-threatening over or under-treatment.

- Goal-directed endpoints for further management determined using invasive haemodynamics.

\section{Optimization Phase}

- Second phase of resuscitation

- Emphasised to ensuring adequate blood and oxygen delivery to at-risk organs.

- Intravascular volume homeostasis is maintained.
Avoid unnecessary fluid loading and excessive fluid accumulation with subsequent organ dysfunction or failure.

\section{Stabilisation and De-escalation phase}

- Final stage of fluid resuscitation.

- Fluid removal and active "deresuscitation",

- Corresponding to a state of physiologic stabilization, organ injury recovery and convalescence.

- If allowed to, fluid accumulation may contribute to secondary organ injury and adverse events.

- The patient may only need to be seen once every few hours with the clinician either prescribing i.v. fluids or diuretics accordingly.

\section{References}

1. O'Shaughnessy WB. Proposal of a new method of treating the blue epidemic cholera by the injection of highly-oxygenised salts into the venous system. Lancet 1831;17: 366-71 https://doi.org/10.1016/S0140-6736(02)94163-2

2. Svensen C. Anaesthesia monitoring microvascular reactivity: a tool for guiding fluid therapy. Anaesthesia 2016; 1:743-763

3. Marik PE, Lemson J. Fluid responsiveness: an evolution of our understanding. British Journal of Anaesthesia. 2014;112: 617-20 https://doi.org/10.1093/bja/aet590 PMid:24535603

4. Nicole Siparsky. Uptodate. 2016; Aug.

5. NICE guidelines: Blood transfusion. NG24. 2015; Nov

6. Perel P, Roberts I, Ker K. Colloids versus crystalloids for fluid resuscitation in critically ill patients. Cochrane Data base systematic review 213;2: CD000567.

7. Finfer S1, Bellomo R, Boyce N, et al. SAFE Study Investigators. A comparison of albumin and saline for fluid resuscitation in the intensive care unit. N Engl J Med. 2004 May 27;350(22):2247-56.

https://doi.org/10.1056/NEJMoa040232 PMid: 15163774

8. Finfer S, McEvoy S, Bellomo R, et al. Impact of albumin compared to saline on organ function and mortality of patients with severe sepsis. Intensive Care Med. 2011 Jan;37(1):86-96. https://doi.org/10.1007/s00134-010-2039-6 
PMid:20924555

9. Bellomo R, Morimatsu H, French C, et al. The effects of saline or albumin resuscitation on acid-base status and serum electrolytes. Crit Care Med. 2006 Dec;34(12):2891-7. https://doi.org/10.1097/01.CCM.0000242159.3 2764.86

PMid:16971855

10. Myburgh J, Cooper DJ, Finfer S, et al. Saline or albumin for fluid resuscitation in patients with traumatic brain injury. N Engl J Med. 2007 Aug 30;357(9):874-84.

https://doi.org/10.1056/NEJMoa067514 PMid:17761591

11. De Backer D, Donadello K, Cortes DO. Monitoring the microcirculation. Journal of clinical Monitoring and Computing 2012;26: 361-6.

https://doi.org/10.1007/s10877-012-9383-8

PMid:22833180

12. Sakka SG, Klein M, Reinhart K, et al. Prognostic value of extravascular lung water in critically ill patients.Chest2002;122:2080-6.

https://doi.org/10.1378/chest.122.6.2080

PMid:12475851

13. Brandstrup B. Fluid therapy for the surgical patient. Best Pract Res Clin Anaesthesiol. 2006; 20 (2):265.

https://doi.org/10.1016/j.bpa.2005.10.007 PMid:16850777

14. Corcoran T, Rhodes JE, Clarke S, et al. Perioperative fluid management strategies in major surgery: a stratified meta-analysis. Anesth Analg. 2012;114(3):640.

https://doi.org/10.1213/ANE.0b013e318240d6e b

PMid:22253274

15. Ismail $\mathrm{H}$, Heriot $\mathrm{AG}$, Ho KM. Improving perioperative outcomes: fluid optimization with the esophageal Doppler monitor, a meta analysis and review. J Am Coll Surg. 2008 Dec;207(6):935-41.

16. Corcoran T, Rhodes JE, Clarke S, et al. Goaldirected haemodynamic therapy and gastrointestinal complications in major surgery: a meta-analysis of randomized controlled trials. Br J Anaesth. 2009 Nov;103(5):637-46. https://doi.org/10.1093/bja/aep279 PMid:19837807

17. Grocott MP1, Dushianthan A, Hamilton MA, et al. Perioperative increase in global blood flow to explicit defined goals and outcomes following surgery. Cochrane Database Syst Rev. 2012 Nov 14;11:CD004082.

PMid:23152223

18. Pearse RM, Harrison DA, MacDonald N, et al (OPTIMISE Study Group). Effect of a perioperative, cardiac output-guided hemodynamic therapy algorithm on outcomes following major gastrointestinal surgery: a randomized clinical trial and systematic review. JAMA. 2014 Jun 4;311(21):2181-90. https://doi.org/10.1001/jama.2014.5305 PMid:24842135

19. Brandstrup B1, Svendsen PE, Rasmussen M, et al. Which goal for fluid therapy during colorectal surgery is followed by the best outcome: nearmaximal stroke volume or zero fluid balance.

BrJAnaesth.2012Aug;109(2):191-9. https://doi.org/10.1093/bja/aes163 PMid:22710266

20. Ford N, Hargreaves S, Shanks L. Mortality after fluid bolus in children with shock due to sepsis or severe infection: a systematic review and meta-analysis. PLoS One. 2012;7(8): e43953. Review. PubMed PMID: 22952819; PubMed Central PMCID: PMC3431361.

21. Hoste E, Maitland K, Brudney J, Vincent JL et al :Four phases of intravenous fluid therapy: a conceptual mode. Br. J. Anaesth. 2014;113 (5):740-747

https://doi.org/10.1093/bja/aeu300

PMid:25204700

22. Guidelines on Clinical Management of Dengue - part 2. Weekly epidemiological report. Epidemiology unit, ministry of health, Sri Lanka. Vol. 36 No.53 26th December- 01st January 2010

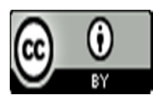

(C) 2017. Warnapura et al. This is an Open Access article distributed under the terms of the Creative Commons Attribution License (http: //creativecommons.org/licenses/by/4. 0), which permits unrestricted use, distribution, and reproduction in any medium, provided the original work is properly credited 